\title{
Anti-platelet Therapy Resistance - Concept, Mechanisms and Platelet Function Tests in Intensive Care Facilities
}

\author{
Alina Mărginean ${ }^{1,2}$, Claudia Bănescu ${ }^{1 *}$, Alina Scridon ${ }^{1}$, Minodora Dobreanu ${ }^{1}$ \\ 1 University of Medicine and Pharmacy of Tîrgu Mures, Romania \\ 2 Emergency Military Hospital "Dr. Constantin Papilian”, Cluj-Napoca, Romania
}

\begin{abstract}
It is well known that critically ill patients require special attention and additional consideration during their treatment and management. The multiple systems and organ dysfunctions, typical of the critical patient, often results in different patterns of enteral absorption in these patients. Anti-platelet drugs are the cornerstone in treating patients with coronary and cerebrovascular disease. Dual anti-platelet therapy with aspirin and clopidogrel is the treatment of choice in patients undergoing elective percutaneous coronary interventions and is still widely used in patients with acute coronary syndromes. However, despite the use of dual anti-platelet therapy, some patients continue to experience cardiovascular ischemic events. Recurrence of ischemic events is partly attributed to the fact that some patients have poor inhibition of platelet reactivity despite treatment. These patients are considered low- or nonresponders to therapy. The underlying mechanisms leading to resistance are not yet fully elucidated and are probably multifactorial, cellular, genetic and clinical factors being implicated. Several methods have been developed to asses platelet function and can be used to identify patients with persistent platelet reactivity, which have an increased risk of thrombosis. In this paper, the concept of anti-platelet therapy resistance, the underlying mechanisms and the methods used to identify patients with low responsiveness to anti-platelet therapy will be highlighted with a focus on aspirin and clopidogrel therapy and addressing especially critically ill patients.
\end{abstract}

Keywords: blood platelets, platelet aggregation inhibitors, aspirin, clopidogrel, cytochrome P-450 enzyme system, platelet function tests

Received: 2 May 2015 / Accepted: 10 July 2015

\section{INTRODUCTION}

Acute cardiovascular events can lead frequently to a critical, life-threatening condition, in case of acute myocardial infarction complicated with cardiogenic schock, critical limb ischemia or acute cerebrovascular events. The critical role of platelets during acute thrombotic events in the context of arterial disease is well established [1]. Anti-platelet drugs have therefore a major role in treating patients with coronary artery disease, ischemic stroke and peripheral arterial disease [2]. According to European Society of Cardiology (ESC) and American Heart Association / American College of Cardiology (AHA/ACC) guidelines, a combination regimen of aspirin and clopidogrel is the treatment of choice in patients undergoing elective percutaneous coronary interventions and is still widely used in patients with acute coronary syndromes [3-5]. However, despite the use of dual anti-platelet therapy, some patients continue to develop cardiovascular ischemic events [6.7]. Recurrent ischemic events are partly attributed to the fact that some patients have poor inhibition of platelet reactivity despite treatment [7]. These patients are considered low- or non-responders ("resistant") to therapy [8]. It is well known that individual responsiveness to clopidogrel and/or aspirin varies widely among patients and is subject to intra- and inter-individual variability $[7,9]$. The un-

\footnotetext{
Correspondence to: Claudia Bănescu, Departament of Medical Genetics, University of Medicine and Pharmacy Tîrgu Mureș, 38 Gheorghe Marinescu St., 540139 , Tîrgu Mures, Romania. E-mail: claudia.banescu@gmail.com

Alina Mărginean, University of Medicine and Pharmacy Tîrgu Mureș, Romania, Department of Laboratory Medicine, 38 Gh Marinescu St., 540139, Tîrgu Mureș, Romania; Emergency Military Hospital "Dr. Constantin Papilian", 22 General Traian Mosoiu St., Cluj-Napoca, 400132, Romania

Alina Scridon, University of Medicine and Pharmacy Tîrgu Mureș, Romania, Physiology Department, 38 Gh Marinescu St., 540139, Tîrgu Mureș, Romania

Minodora Dobreanu, University of Medicine and Pharmacy Tîrgu Mureș, Romania, Department of Laboratory Medicine, 38 Gh Marinescu St., 540139 , Tîrgu Mureș, Romania
} 
derlying mechanisms leading to resistance are not yet fully elucidated and are probably multifactorial $[10,11]$. Different methods have been developed for monitoring response to anti-platelet drugs and for identifying patients with persistent platelet reactivity, which is essential for the development of atherothrombotic complications [12,13].

This article reviews the concept of anti-platelet therapy resistance, the underlying mechanisms including genetic polymorphisms that might influence response to anti-platelet drugs and the methods used to identify patients with low responsiveness to anti-platelet therapy. We will focus on aspirin and clopidogrel based on frequency of use in clinical practice and availability of study data, with a special focus on describing the mechanisms for anti-platelet drugs resistance in critically ill patients.

\section{ANTI-PLATELET DRUGS - MECHANISMS OF ACTION}

\section{Aspirin}

The main cyclooxygenase (COX) product in activated platelets is thromboxane A2 (TxA2) which induces platelet aggregation and acts as a potent vasoconstrictor [14]. At the molecular level, aspirin causes irreversible acetylation of a serine residue in the 529 position of the COX-1 enzyme. This particular enzyme produces the cyclic endoperoxide precursor of TxA2, thereby blocking the thromboxane-mediated pathway. Since platelets lack the synthetic machinery to produce significant amounts of new COX, the effect of aspirin is permanent, throughout the entire life of the platelet, and the inhibitory effect will become cumulative when aspirin is administered once every day $[14,15]$.

Aspirin treatment reduces the number of thrombotic events in high risk patients by almost $25 \%$ [16]. Although aspirin has a proven antithrombotic effect, 10 to $20 \%$ of the patients treated with aspirin have a recurrent arterial thrombotic event during the long-term follow-up [16]. The risk of such event was partly attributed to the fact that aspirin is unable to inhibit platelet function in some patients. This so-called "variability of response" is estimated to occur in as much as $5-60 \%$ of patients [15].

\section{Clopidogrel}

Clopidogrel is an irreversible thienopyridine P2Y12 receptor antagonist, thus inhibitsadenozine diphos- phate (ADP) induced platelet aggregation. It is an inactive pro-drug that requires hepatic cytochrome $\mathrm{P} 450$ (CYP) system oxidation to release its active metabolite, which binds irreversibly through covalent modification to the ADP-coupled P2Y12 receptor [15]. There is considerable inter-individual variability in response to clopidogrel, current data suggesting that about $10 \%$ to $50 \%$ of patients treated with conventional doses do not display adequate anti-platelet response [17-20]. Four independent meta-analyses studiesemphasised the association between high non-clopidogrel platelet reactivity and significant increase in stent thrombosis, non-fatal myocardial infarction and cardiovascular mortality [21-24].

\section{THE CONCEPT OF ANTI-PLATELET RESIST- ANCE}

Anti-platelet resistance can be classified as a laboratory or clinical phenomenon [25]. Laboratory resistance to aspirin may be defined as a failure to inhibit platelet TxA2 production following inhibition of platelet COX1 enzyme [25,26]. Laboratory resistance to thienopyridine refers to the inability to obtain reduction in ADPmediated platelet aggregation after blocking P2Y12 receptor signalling [6].

Clinical resistance to anti-platelet drugs can be defined as failure to prevent clinical atherothrombotic events which may also be referred to as treatment failure [25].

\section{MECHANISMS FOR ANTI-PLATELET DRUGS RESISTANCE}

Possible causes for anti-platelet treatment failure include the following categories:

\section{Reduced bioavailability of anti-platelet drugs}

Noncompliance is probably the major cause of antiplatelet therapy "resistance" $[27,28]$. Cigarette smoking, depression, diabetes mellitus, low education level and female sex were identified as predictors of noncompliance and treatment discontinuation [29]. Reduced bioavailability due to poor drug absorptionis the principal factor which determines the response to aspirin [26].

Thereareseveraldifferentpharmaceuticalformulations of aspirin [26]. Optimal absorption of aspirin occurs at $\mathrm{pH}$ values between 2 and 4 . Enteric-coated aspirin is ab- 
sorbed in the small intestine. It has been demonstrated that a higher $\mathrm{pH}$, of 6 to 7 , found in the small intestine, both delays and reduces absorption which in turn diminishes the aspirin inhibitory effect [30].

A major issue in the field of anti-platelet therapy resistance is represented by potential drug interactions. Concurrent administration of nonsteroidal anti-inflammatory drugs (e.g. ibuprofen, indomethacin) may interfere with aspirin's anti-thrombotic effect by blocking its docking site on COX-1 [31]. Proton pump inhibitors (PPIs), that suppress gastric acid secretion, may reduce the bioavailability of aspirin due to inactivation of the drug by gastrointestinal mucosal esterases thus reducing its absorption [32]. PPIs are substrates and competitive inhibitors of CYP2C19, the hepatic isoenzyme that plays a major role in the activation of clopidogrel. Consequently, concomitant use of clopidogrel and PPIs, in particular omeprazole and esomeprazole, reduces clopidogrel active metabolite levels and ex vivo measured platelet inhibition $[33,34]$. Although some studies suggest that concomitant therapy with PPIs and clopidogrel is associated with an increased risk of cardiovascular events $[18,35,36]$, a clinically meaningful effect of this interaction on cardiovascular outcomes has not been established [33]. However, since a clinical significant interaction cannot be completely excluded, Food and Drug Administration (FDA) recommends avoiding omeprazole and esomeprazole in patients treated with clopidogrel [34]. It has been suggested that there is a possible pharmacokinetic interaction between clopidogrel and statins [31]. There is some evidence that this interaction is more likely with lipophilic statins - simvastatin [37], atorvastatin [38,39] and lovastatin [40], which share the same CYP metabolizing isoenzyme, CYP3A4. However, randomized clinical trials failed to detect a clinically relevant effect of clopidogrel and statin combined administration [41]. Dihydropyridine calcium-channel blockers another frequently used class of cardiovascular drugs, are also CYP3A4 inhibitors [42]. Coadministration of dihydropyridine calcium-channel blockers, e.g., amlodipine, has been associated with decreased platelet inhibition by clopidogrel [43]. However, large clinical trials excluded the clinical importance of this interaction [41].

\section{Genetic polymorphisms}

Genetic polymorphisms is one of the most widely studied mechanism involved in the phenomenon of anti- platelet therapy resistance [3]. It is believed that up to $30 \%$ of the variability in platelet activity can be attributed to genetic factors [44].

In order to determine if there is a genetic basis of aspirin resistance, all genetic studies on aspirin resistance, including both healthy subjects and patients with cardiovascular disease, were reviewed [45]. Fifty polymorphisms in eleven genes were investigated. In case of healthy subjects, they demonstrated a significant association between aspirin resistance and P1A1/A2 polymorphism (glycoprotein (GP) IIIa receptor gene), with the effect diminishing in case of patients with cardiovascular disease. On the other hand, no significant association with different variants of COX-1, P2Y1, P2Y12 and GP-1a genes was found. Thus, there was a failure to identify any clinically significant genetic contribution to aspirin response [46]. In a multivariate analysis, variant homozygous CC genotype AGT A-20C (rs50505) patients, treated with low dose aspirin, were shown to be more prone to have reactive gastropathy and bleeding ulcers in a population with a high prevalence of Helicobacter pylori infection [47].

Clopidogrel is a prodrug that requires hepatic activation. The formation of the active metabolite, a twostep process, is catalysed by several CYP isoenzymes including CYP2C19, CYP1A2, CYP3A4/5, CYP2B6, and CYP2C9 [48]. The genes encoding CYP isoenzymes are polymorphic with specific alleles that are associated with decreased enzymatic activity and, as a consequence, reduced production of the active metabolite [49].

Common polymorphisms in the CYP2C19 gene, seen in $30-55 \%$ of the population depending on the genetic background and ethnic group, significantly diminish response to clopidogrel [50,51]. Clinical studies confirmed the impact of CYP2C19 genotype on clinical outcomes [50,52]. Moreover, in 2010, FDA issued a warning informing that clopidogrel can be less effective in patients carrying the CYP2C19*2 loss-of-function allele (the so called poor metabolizers) and that available tests to identify genetic differences in CYP2C19 function could be used [53]. Genetic variations in other CYP enzymes involved in clopidogrel metabolic activation or in the drug target, the P2Y12 ADP receptor were not consistently associated with a risk of an adverse outcome $[46,52]$.

There are studies stipulating that the response tooral anticoagulanttreatment could be affected by polymorphisms of the genes encoding cytochrome P450 2C9 
(CYP2C9) enzymes and vitamin $\mathrm{K}$ epoxide reductase complex subunit 1 (VKORC1) [54]. Most of the studies demonstrated that VKORC1-1639AA and CY$\mathrm{P} 2 \mathrm{C} 9 * 3 * 3$ alleles are associated with the need for a lower dose of acenocoumarol, especially if polymorphisms of CYP2C9 + VKORC1 coexist [55]. The C3435T polymorphism in $\mathrm{ABCB} 1$, the gene encoding for the $\mathrm{P}$ glycoprotein drug transporter involved in clopidogrel absorption, has been associated with reduced plasma concentration of clopidogrel and its active metabolite and with a 1.7-fold greater cardiovascular event rate in patients after acute myocardial infarction [52].

\section{Alternative pathways of platelet activation}

A mechanism that can cause increased baseline platelet reactivity and in consequence anti-platelet therapy resistance is activation of platelets through COX-1 or P2Y12- independent pathways, e.g. in case of infection, inflammatory disorders, and atherosclerosis $[25,26,56,57]$.

\section{Accelerated platelet turnover}

Accelerated platelet turnover, as in case of bleeding or stress, is another cause of reduced platelet response to anti-platelet drugs, and is due to the addition of platelets that have not been previously exposed to the action of aspirin orclopidogrel [26].

\section{Mechanisms for anti-platelet drugs resistance in critically ill patients}

It is well known that critically ill patients require special attention and additional consideration during their treatment and management. The multiple systems and organ dysfunctions, typical of the critical patient, often results in different patterns of enteral absorption due to impaired gastric emptying, diminished hepatic metabolising capability, impaired splanchnic blood flow, increased total body water, reduced plasma proteins for drug binding, decreased fat stores, reduced microsomal enzyme activity and multiple drug interactions. Additionally there is the issue of inadequate drug formulations and routes of administration that will be discussed further (Figure 1).

The critical patient often needs to be sedated for long periods of time. Different drugs used for this purpose, including, but not limited to, morphine and its derivatives \pm midazolam, reduce gastrointestinal motility and impede gastric emptying [58]. Also anxiety and stress seems to have a similar effect on gastric motility [59]. Clopidogrel is mainly absorbed in the intestinal portion of the digestive tract which means that reduced gastric motility may moderate its absorption [60].

Because of the hepatic dysfunction sometimes present, the two-phase enzymatic activation of clopidogrel

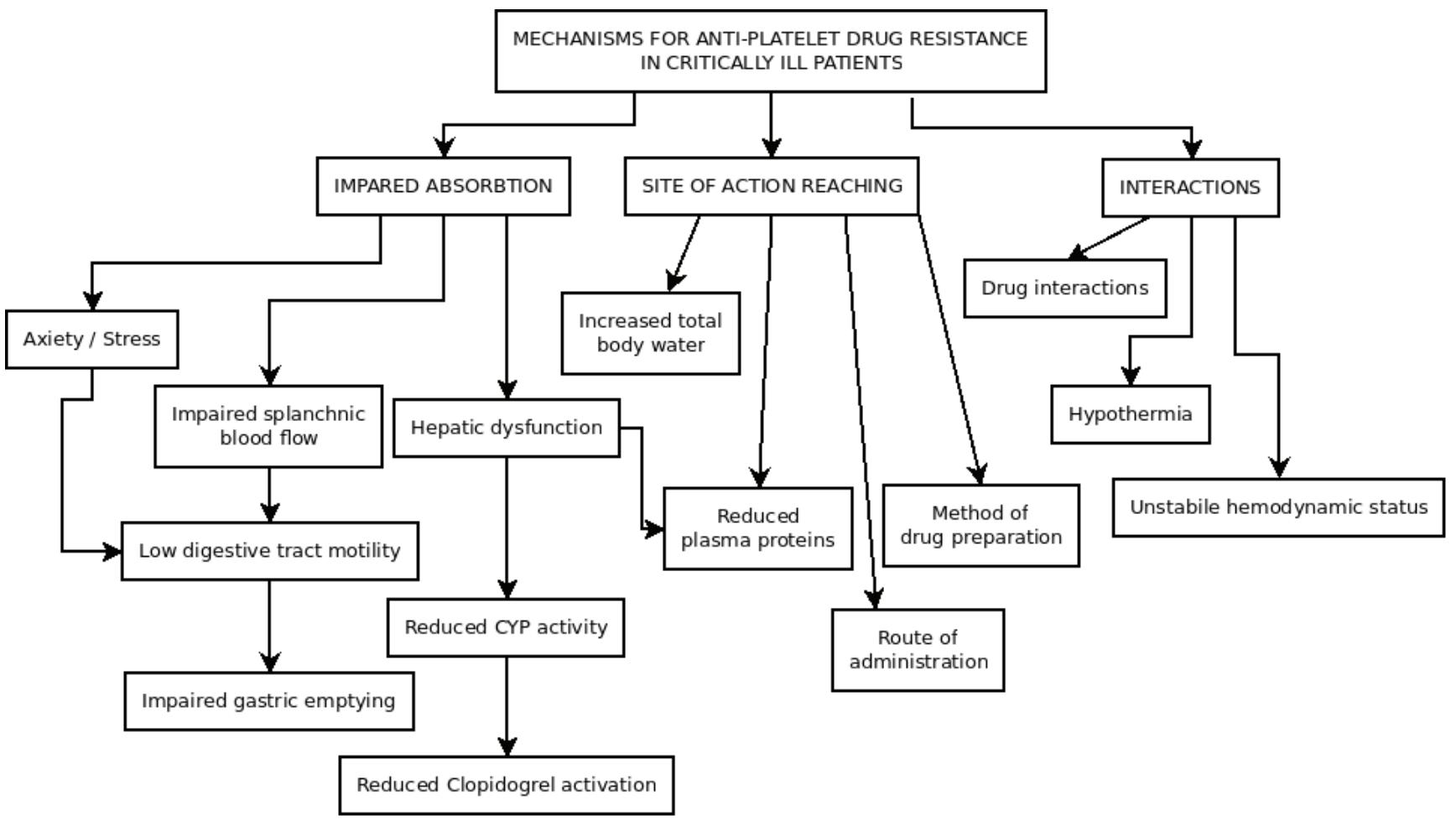

Figure 1. Mechanisms for anti-platelet resistance in critically ill patients 
is severely impaired resulting in lower plasma levels and sub-optimal platelet function inhibition. Patients with this problem are more prone to develop hypoproteinemia/hypoalbuminemia which further influences pharmacokinetics, as clopidogrel is highly protein bound [61].

For the critical patient it is often difficult to manage fluid balance. Patients could be severely dehydrated at admission, with third space shifting, e.g. severe sepsis, septic shock, or a positive balance after fluid resuscitation. All these variations make it hard to evaluate the volume of drug distribution and add to the complexity of anti-platelet drug dosing and management.

Though there is debate regarding this approach, induced and controlled hypothermia is still used as a management strategy for patients surviving cardiac arrest [62]. Bjelland et al. showed that after therapeutic hypothermia the effect of clopidogrel is non-existent in the first day of treatment and during the third day the recovery in partial [63]. Also there is evidence that bioavailability of clopidogrel is reduced in hemodynamic unstable patients after successful cardio-pulmonary resuscitation [64].

Because of the nature of the disease, this subset of patients often receive multiple drugs belonging to a multitude of pharmacological classes. It is always useful to check if other prescribeddrugs are safe from unwarranted interactions with clopidogrel. In this regard, Oguet al. provided a good resource of drug interactions due to cytochrome P450 inhibitors or inducers [65]. An enzyme inhibitor will reduce the activation of the pro-drug thus reducing clopidogrel action. On the other hand, inducers of CYP450 iso-enzymes will increase clopidogrel inhibitory action. The most frequently used inhibitors in critical care facilities are ciprofloxacin, erythromycin (often administered as a pro-kinetic drug), omeprazole, amiodarone, fluconazole (prophylaxis of invasive candidiasis after long-term antibiotic therapy), isoniazid, metronidazole, sulfamethoxazole/ trimethoprim, haloperidol, propafenone, grapefuit juice (could be found in home-made enteral nutrition), and verapamil. Inducers include, carbamazepine, phenobarbital, rifampin and isoniazid.

It should be noted that the chronic use of ethanol and/or tobacco is also an important inducer of CYP activity.

One possibly overlooked interaction, that may affect critical patients, is with omega-3 fatty acids (n-3 fatty acids, polyunsaturated fatty acids - PUFA; $\alpha$-linolenic, eicosapentaenoic and docosahexaenoic acid) which are known to have inhibitory effects on platelet function,66 creating an additional anti-platelet effect. The presence of omega- 3 fatty acids seems to be increasing in parenteral nutrition formulations (e.g. SmofKabiv$\left.e^{\circledast}\right)$. Although this is still open for debate [67], caution is advised.

Clopidogrel has no parenteral formulation. This means that an enteral feeding tube is often required and in order to make the administration possible. The tablets need to be crushed, suspended in some liquid and flushed down the tube. Even if the administration itself is performed correctly, (stop on-going enteral feed, flush the enteral feeding tube with $15 \mathrm{~mL}$ of sterile water, flush medication, draw another $10 \mathrm{~mL}$ of sterile water into the syringe and also flush this via the feeding tube to rinse the syringe and ensure that the total dose is administered) [68] there is evidence to show that the method used to crush the tablet may influence the bioavailability of the drug. The mortar and pestle method delivers the smallest amount of available powdered drug and is prone to the highest inconsistency among different individuals [69]. Thus, it is recommended that the tablet is placed in the barrel of an appropriate size syringe, $10 \mathrm{~mL}$ of sterile water should then be drawn into the syringe allowing the tablet to disperse for up to 6 minutes, shaking if necessary and then administer as described above. To overcome these bioavailability problems several attempts at designing solubility enhancements for clopidogrel have been madewith satisfactory results, one of which is the creation of microemulsions [70].

\section{LABORATORY METHODS FOR MONITOR-}

\section{ING ANTI-PLATELET THERAPY}

Several methods for platelet function testing are currently available.Some of them are laboratory based, (e.g. light transmission platelet aggregometry - LTA, flow cytometry) while some are point of care tests (e.g. Platelet function analyser -100 system (PFA-100)/ Innovance PFA-200, VerifyNow Test, Impedance aggregometry) $[14,71]$.

The most commonly used platelet function tests are summarised below.

\section{Bleeding time}

Dating from 1901, bleeding time is used to assess in vivo platelet function and the body's capacity to form a hae- 
mostatic clot. The test involves performing a puncture wound in a superficial area of the skin and measuring the time needed for bleeding to stop. Unfortunately, no study has demonstrated a correlation between bleeding time and risk of bleeding or thrombosis [14]. Bleeding time is inaccurate, poorly reproducible and dependent on certain variables such as temperature and skin thickness [14,72].

\section{Light transmission platelet aggregometry (LTA)}

Light Transmission Aggregometryor low shear aggregometry, is a method developed in the 1960s, and is regarded as the gold standard test for assessing platelet function and is still utilised to validate newer tests $[26,73]$. LTA is performed on platelet rich plasma and measures changes that occur in light transmittance after platelet-platelet aggregation as a response to the addition of several agonists (ADP, arachidonic acid, collagen, epinephrine, ristocetin, thrombin receptor activating peptide etc) $[26,73]$. It can be used to monitor therapy with aspirin, thienopyridines and GPIIb/ IIIa inhibitors. Despite the widespread use of LTA, there are certain aspects of this technique that limit its use as a reliable and valid method to evaluate platelet function [26]. These include poor reproducibility, low sensitivity, difficulty to standardize, high costs, operator dependency, large sample volumes, complex sample preparation and long processing times [25,74,75].

\section{Flow cytometry}

Platelet analysis using flow cytometry, a conjugated monoclonal antibody based technique, may offer information on the functional status of platelets. Flow cytometry assay has many applications and can be used to identify the pathological activation state of platelets e.g. during cardiopulmonary bypass, to assess in vitro platelet activation, to evaluate the efficacy of anti-platelet therapy, to diagnose acquired or inherited platelet dysfunctions [76]. Membrane GP receptors of platelets can also be studied. Vasodilator, stimulated phosphoprotein (VASP) phosphorylation, is a method that measures activation-dependent platelet signalling. It is the most specific test used to assess the extent to which P2Y12 receptors are functionally blocked by a P2Y12 antagonist [31]. There are also methods that can be used to measure activation dependent modifications or activation markers, on the surface of platelets. These tests include the assessment of platelet surface P-selectin levels, activated GPIIb/IIIa and platelet - leukocyte clumping [31]. Despite its complex sample preparation and high costs [76], the flow cytometry technique is favoured due to the fact that it uses whole blood, small sample volumes, has a wide range of applications and high accuracy and a good correlation with LTA [77].

\section{Platelet function analyser -100 system (PFA-100)/In- novance PFA-200}

The PFA - 100 and the updated version Innovance PFA200 (Siemens, Marburg, Germany), were developed for platelet dysfunction screening as a standardised alternative to the bleeding time $[78,79]$. Using appropriate cartridges, platelet function analyser simulates primary haemostasis. Citrated whole blood is passed under high shear stress through a microscopic aperture coated with collagen and an agonist, ADP or epinephrine [73]. As the blood passes through the system, platelets undergo adhesion and aggregation, a platelet clot forms and gradually occludes the opening. The time required to close the microscopic opening is called in vitro bleeding time or closure time [26]. The system is automated, easy to use and quick. The drawbacks of the PFA - 100 system are that many variables can affect the results including haematocrit, platelet count, and plasma von Willebrand factor. It also has limited sensitivity and reliability $[77,80]$.

\section{VerifyNow Test}

VerifyNow system (Accumetrics, CA, USA) is a pointof-care device that measures platelet aggregation in a system cartridge which incorporates fibrinogen-coated beads and a specific agonist. The instrument measures changes in optical signal intensity i.e. light transmission, and records the rate of aggregation in citrated whole blood [77]. The system provides three assays: (1). GPIIb/IIIa assay that uses iso-thrombin-receptor activating peptide as agonist and is sensitive to GPIIb/ IIIa inhibitors; (2) P2Y12 assay, sensitive to thienopyridines, with ADP as the agonist in the presence of prostaglandin E1 which abolishes signalling through P2Y1 receptors; and (3) Aspirin assay, i.e. sensitive to aspirin, with arachidonic acid asthe antagonist [73]. Given the fact that the system is based on the same concept as LTA, these two correlate well [81]. Its advantages are that it is standardised, easy to use, and requires no sample processing. On the other hand, the system can be used only for monitoring anti-platelet therapy and is limited by platelet count and haematocrit as well as being is expensive [81]. 
Impedance aggregometry

Impedance aggregometry is based on the principle that activated platelets display their surface receptors which allow them to attach to artificial surfaces [73]. This test measures the change in impedance between two electrodes within a whole blood sample. After adding a specific agonist, platelets adhere to the electrodes thus increasing the impedance or electrical resistance. Multiple Platelet Function Analyser or Multiple Electrode Aggregometry (Multiplate ${ }^{\circledast}$ - Dynabyte - Roche Diagnostics, Germany) is the automated version of impedance aggregometry. The advantages of whole blood impedance platelet aggregometry are that this is a diagnostic method for platelet surface glycoprotein defects, has good sensitivity for anti-platelet drugs, which are used to monitor therapy with thienopyridines, aspirin and GPIIb/IIIa inhibitors, functions with a variety of different available agonists and the samples require no preparation [73]. Limitations are due to the fact that the number of platelets should be above $100,000 / \mathrm{mi}$ croliter when testing is performed [26].

The Working Group on Thrombosis of the ESC reviewed the role of platelet function testing in patients undergoing coronary stenting in a paper published in the European Heart Journal in 2014. The consensus summary stated that "based on the currently available evidence, the recommended assays for monitoring platelet inhibition during P2Y12-inhibitors are the VerifyNow P2Y12 assay, the Multiplate device with the ADP kit and the VASP assay". Light transmission platelet aggregometry "is only recommended when no standardized assays are available". Regarding testing the efficacy of aspirin therapy in these patients the consensus states that measurement of response to this therapy is not recommended [82].

\section{- TESTING PLATELET FUNCTION IN PERIOP- ERATIVE AND CRITICAL CARE SETTINGS}

Several whole blood point-of care tests have been demonstrated to be valuable tools in different clinical settings including critical care facilities [83]. The potential advantages of these tests are rapid turnaround time, simplified workflows, and targeted management of coagulation disorders.

In severe sepsis, Adamzik et al [84] demonstrated, in an observational cohort study, that impedance ag- gregometry allows a better prediction of diagnosis and survival than platelet count and conventional biomarkers like procalcitonin, interleukin 6, C-reactive protein.

A retrospective study on trauma patients, chronically treated with clopidogrel, showed that the VerifyNow P2Y12 assay may be useful in stratifying patients with a higher risk of bleeding [85].

A recent study [86] performed on orthopaedic patients, presenting with acute proximal femoral fracture, demonstrated the utility of impedance aggregometry in identifying non-responders to clopidogrel therapy. In case of non-responsiveness, these patients can be operated without delay. It is well known that delayed surgery is associated with both increased mortality and increased frequency of complications.

In cardiac surgery, perioperative platelet functional assessment using point-of-care devices like Multiplate ${ }^{\oplus}$ or VerifyNow system, can predict blood loss and transfusion requirements in patients treated with anti-platelet drugs $[87,88]$.

In case of patients undergoing percutaneous coronary intervention, impedance aggregometry can predict stent thrombosis and early mortality [89].

\section{CONCLUSION}

Aspirin and clopidogrel, two widely used anti-platelet agents with good antithrombotic activity, provide a significant benefit to patients with cardiovascular disease. Evidence of variability in platelet response has led to the concept of anti-platelet therapy resistance. Poor responsiveness or resistance to aspirin and clopidogrel, an emerging clinical entity, is associated with increased risk of recurrent cardiovascular events. Resistance to anti-platelet drugs has been characterized as a laboratory or clinical phenomenon. Genetic testing can identify poor metabolizers of clopidogrel. It is important to also keep in mind that multiple other factors can contribute to the variability of response to anti-platelet therapy.

Although several assays for assessing platelet activity are available, there is no perfect test for platelet function. Light transmission aggregometry, considered the gold standard test, has its limitations. On the other hand, standardised point of care tests may assist in individualising anti-platelet therapy and can be used to asses haemostatic status of critically ill patient. 


\section{- ABBREVIATION LIST}

ACC American College of Cardiology

ADP adenosinediphosphate

AHA American Heart Association

COX-1 cyclooxygenase-1

CYP cytochrome P450

ESC European Society of Cardiology

FDA Foodand Drug Administration

GP glycoprotein

LTA LightTransmissionAggregometry

PFA Plateletfunctionanalyser

PPIs proton pump inhibitors

TxA2 thromboxane A2

VASP Vasodilator-stimulatedphosphoprotein

\section{ACKNOWLEDGEMENT}

This paper is supported by the Sectorial Operational Programme Human Resources Development (SOP HRD), financed from the European Social Fund and by the Romanian Government under the contract number POSDRU/159/1.5/S/133377.

\section{REFERENCES}

1. Vögtle T, Cherpokova D, Bender M, Nieswandt B. Targeting platelet receptors in thrombotic and thrombo-inflammatory disorders. Hamostaseologie. 2015;35 [Epub ahead of print]

2. Floyd CN, Ferro A. Anti-platelet drug resistance: Molecular insights and clinical implications. Prostaglandins Other Lipid Mediat. 2015; [Epub ahead of print]

3. Vlachojannis GJ, Dimitropoulos G, Alexopoulos D. Clopidogrel resistance: current aspects and future directions. Hell J Cardiol. 2011;52:236-45.

4. Amsterdam EA, Wenger NK, Brindis RG, et al. 2014 AHA/ ACC Guideline for the Management of Patients With NonST-Elevation Acute Coronary Syndromes. J Am Coll Cardiol. 2014;64:e139-228.

5. Steg PG, James SK, Atar D, et al. ESC Guidelines for the management of acute myocardial infarction in patients presenting with ST-segment elevation. Eur Heart J. 2012;33:2569-619.

6. Pyrgakis VN, Goudevenos JA. Clopidogrel and cardiovascular diseases: recommendations for its correct use. Hell J Cardiol. 2010;51:83-6.

7. Angiolillo DJ, Fernandez-Ortiz A, Bernardo E, et al. Variability in individual responsiveness to clopidogrel: clinical implications, management, and future perspectives. J Am Coll Cardiol. 2007;49:1505-16.
8. Papathanasiou A, Goudevenos J TAD. Resistance to Aspirin and Clopidogrel: Possible Mechanisms, Laboratory Investigation, and Clinical Significance. Hell J Cardiol. 2007;48:352-63.

9. Dupont AG, Gabriel DA, Cohen MG. Anti-platelet therapies and the role of anti-platelet resistance in acute coronary syndrome. Thromb Res. 2009;124:6-13.

10. Abacı O, Kılıçkesmez KO. Aspirin resistance: Where are we now? Anadolu Kardiyol Derg. 2013;13:370-3.

11. Karaźniewicz-Łada M, Danielak D, Główka F. Genetic and nongenetic factors affecting the response to clopidogrel therapy. Expert Opin Pharmacother. 2012;13:663-83.

12. Abbate R, Crea F, De Servi S, et al. [Extent of platelet aggregation inhibition and clinical events: new evidence with prasugrel]. G Ital Cardiol. 2010;11:127-37.

13. Fileti L, Campo G, Valgimigli M. Latest clinical data on testing for high on-treatment platelet reactivity. Rev Cardiovasc Med. 2011;12(Suppl 1):S14-22.

14. Saraf S, Bensalha I, Gorog DA. Anti-platelet Resistance - Does it Exist and How to Measure it ? Clin Med Cardiol. 2009;3:77-91.

15. Ahluwalia K, Bhanwra S. Anti-platelet therapy: present status and its future directions. Int J Basic Clin Pharmacol. 2014;3:260.

16. Patrono C, Coller B, FitzGerald G A., Hirsh J, Roth G. Plateletactive drugs: The relationships among dose, effectiveness, and side effects- The Seventh ACCP Conference on Antithrombotic and Thrombolytic Therapy. Chest. 2004;126(3 Supl).

17. Bagoly Z, Sarkady F, Magyar T, et al. Comparison of a New P2Y12 Receptor Specific Platelet Aggregation Test with Other Laboratory Methods in Stroke Patients on Clopidogrel Monotherapy. PLoS One. 2013;8:1-11.

18. Huang B, Huang Y, Li Y, et al. Adverse cardiovascular effects of concomitant use of proton pump inhibitors and clopidogrel in patients with coronary artery disease: a systematic review and meta-analysis. Arch Med Res. 2012;43:212-24.

19. Bonello L, Tantry US, Marcucci R, et al. Consensus and future directions on the definition of high on-treatment platelet reactivity to adenosine diphosphate. J Am Coll Cardiol. 2010;56:919-33.

20. Mallouk N, Labruyère $C$, Reny J-L, et al. Prevalence of poor biological response to clopidogrel: a systematic review. Thromb Haemost. 2012;107:494-506.

21. Aradi D, Komócsi A, Vorobcsuk A, et al. Prognostic significance of high on-clopidogrel platelet reactivity after percutaneous coronary intervention: systematic review and meta-analysis. Am Heart J. 2010;160:543-51.

22. Combescure $C$, Fontana $P$, Mallouk N, et al. Clinical implications of clopidogrel non-response in cardiovascular patients: a systematic review and meta-analysis. J Thromb Haemost. 2010;8:923-33.

23. Sofi F, Marcucci R, Gori AM, Giusti B, Abbate R, Gensini GF. Clopidogrel non-responsiveness and risk of cardiovascular morbidity: An updated meta-analysis. Thromb Haemost. 2010;103:841-8.

24. Brar SS, Ten Berg J, Marcucci R, et al. Impact of platelet reactivity on clinical outcomes after percutaneous coronary intervention. A collaborative meta-analysis of individual participant data. J Am Coll Cardiol. 2011;58:1945-54. 
25. Hankey GJ, Eikelboom JW. Aspirin resistance. Lancet. 2006;367:606-17.

26. Topçuoglu MA, Arsava EM, Ay H. Anti-platelet resistance in stroke. Expert Rev Neurother. 2011;11:251-63.

27. Schwartz KA, Schwartz DE, Barber K, Reeves M, De Franco AC. Non-compliance is the predominant cause of aspirin resistance in chronic coronary arterial disease patients. J Transl Med. 2008;6:46.

28. Serebruany V, Cherala G, Williams C, et al. Association of platelet responsiveness with clopidogrel metabolism: role of compliance in the assessment of "resistance". Am Heart J. 2009;158:925-32.

29. Herlitz J, Tóth PP, Naesdal J. Low-dose aspirin therapy for cardiovascular prevention: quantification and consequences of poor compliance or discontinuation. Am J Cardiovasc Drugs. 2010;10:125-41.

30. Grosser T, Fries S, Lawson JA, Kapoor SC, Grant GR, FitzGerald GA. Drug resistance and pseudoresistance: an unintended consequence of enteric coating aspirin. Circulation. 2013;127:377-85.

31. Feher G, Feher A, Pusch G, et al. Clinical importance of aspirin and clopidogrel resistance. World J Cardiol. 2010;2:171-86.

32. Mansour K, Taher AT, Musallam KM, Alam S. Aspirin resistance. Adv Hematol. 2009;2009:1-10.

33. Scott SA, Owusu Obeng A, Hulot J-S. Anti-platelet drug interactions with proton pump inhibitors. Expert Opin Drug Metab Toxicol. 2014;10:175-89.

34. Johnson DA, Chilton R, Liker HR. Proton-pump inhibitors in patients requiring anti-platelet therapy: new FDA labeling. Postgrad Med. 2014;126:239-45.

35. Juurlink DN, Gomes T, Ko DT, et al. A population-based study of the drug interaction between proton pump inhibitors and clopidogrel. CMAJ. 2009;180:713-8.

36. Stockl KM. Risk of Rehospitalization for Patients Using Clopidogrel With a Proton Pump Inhibitor. Arch Intern Med. 2010;170:704.

37. Neubauer H, Günesdogan B, Hanefeld C, Spiecker M, Mügge A. Lipophilic statins interfere with the inhibitory effects of clopidogrel on platelet function - A flow cytometry study. Eur Heart J. 2003;24:1744-9.

38. Park Y, Jeong Y-H, Tantry US, et al. Accelerated platelet inhibition by switching from atorvastatin to a non-CYP3A4-metabolized statin in patients with high platelet reactivity (ACCEL-STATIN) study. Eur Heart J. 2012;33:2151-62.

39. Pelliccia F, Rosano G, Marazzi G, et al. Pharmacodynamic comparison of pitavastatin versus atorvastatin on platelet reactivity in patients with coronary artery disease treated with dual anti-platelet therapy. Circ J. 2014;78:679-84.

40. Hedegaard SS, Hvas A-M, Grove EL, et al. Optical platelet aggregation versus thromboxane metabolites in healthy individuals and patients with stable coronary artery disease after low-dose aspirin administration. Thromb Res. 2009;124:96-100.

41. Ojeifo O, Wiviott SD, Antman EM, et al. Concomitant administration of clopidogrel with statins or calcium-channel blockers: insights from the TRITON-TIMI 38 (trial to assess improvement in therapeutic outcomes by optimizing platelet inhibition with prasugrel-thrombolysis in myocardial infarctio. JACC Cardiovasc Interv. 2013;6:1275-81.

42. Katoh M, Nakajima M, Shimada N, Yamazaki H, Yokoi T. Inhibition of human cytochrome P450 enzymes by 1,4-dihydropyridine calcium antagonists: prediction of in vivo drug-drug interactions. Eur J Clin Pharmacol. 2000;55:843-52.

43. Seo K-D, Kim YD, Yoon Y-W, Kim J-Y, Lee K-Y. Anti-platelet effect of clopidogrel can be reduced by calcium-channel blockers. Yonsei Med J. 2014;55:683-8.

44. Feher G, Feher A, Pusch G, Lupkovics G, Szapary L, Papp E. The genetics of anti-platelet drug resistance. Clin Genet. 2009;75:1-18.

45. Goodman T, Ferro A, Sharma P. Pharmacogenetics of aspirin resistance: A comprehensive systematic review. $\mathrm{Br} J$ Clin Pharmacol. 2008;66: 222-32.

46. Altman R, Flockhart D, Goldstein D. Principles of pharmacogenetics and pharmacogenomics. 1st ed. 2012;1214.

47. Negovan A, Voidăzan S, Pantea M, et al. AGT A-20C (rs5050) gene polymorphism and ulcer occurrence in patients treated with low-dose aspirin: a case-control study. Rev Romana Med Lab. 2015;23:179-87.

48. Kazui M, Nishiya Y, Ishizuka T, et al. Identification of the human cytochrome P450 enzymes involved in the two oxidative steps in the bioactivation of clopidogrel to its pharmacologically active metabolite. Drug Metab Dispos. 2010;38:92-9.

49. Kim KA, Park PW, Hong SJ, Park J-Y. The effect of CYP2C19 polymorphism on the pharmacokinetics and pharmacodynamics of clopidogrel: a possible mechanism for clopidogrel resistance. Clin Pharmacol Ther. 2008;84:236-42.

50. Mega JL, Close SL, Wiviott SD, et al. Cytochrome P-450 Polymorphisms and Response to Clopidogrel. N Engl J Med. 2009;360:354-62.

51. Varenhorst C, James S, Erlinge D, et al. Genetic variation of CYP2C19 affects both pharmacokinetic and pharmacodynamic responses to clopidogrel but not prasugrel in aspirintreated patients with coronary artery disease. Eur Heart J. 2009;30:1744-52.

52. Simon T, Céline V, Murielle M-K, et al. Genetic Determinants of Response to Clopidogrel and Cardiovascular Events. N Engl J Med. 2009;360:363-75.

53. Seip RL, Duconge J, Ruaño G. Implementing genotype-guided antithrombotic therapy. Future Cardiol. 2010;6:409-24.

54. Militaru FC, Vesa ŞC, Crişan S, Militaru V, Trifa AP, Buzoianu AD. Genotype-phenotype correlations in patients treated with acenocoumarol. Rev Romana Med Lab. 2014;22:347-54.

55. Limdi NA, Wiener $H$, Goldstein JA, Acton RT, Beasley TM. Influence of CYP2C9 and VKORC1 on warfarin response during initiation of therapy. Blood Cells Mol Dis. 2009;43:119-28.

56. Michelson AD, Cattaneo M, Eikelboom JW, Gurbel P. Aspirin resistance: position paper of the Working Group on Aspirin Resistance. Haemostasis. 2005;3:1309-11.

57. Gasparyan AY, Watson T, Lip GYH. The role of aspirin in cardiovascular prevention: implications of aspirin resistance. J Am Coll Cardiol. 2008;51:1829-43.

58. Nguyen NQ, Chapman MJ, Fraser RJ, et al. The effects of sedation on gastric emptying and intra-gastric meal distribution 
in critical illness. Intensive Care Med. 2008;34:454-60.

59. Hong J-Y, Oh JI. Effects of preoperative anxiety on gastric fluid acidity and volume. J Korean Med Sci. 2005; 20:232-5.

60. Roush Ja. The role of the stomach in drug absorption as observed via absorption rate analysis. Int J Pharm. 2014;471:112-7.

61. Ganesan S, Williams C, Maslen CL, Cherala G. Clopidogrel variability: role of plasma protein binding alterations. $\mathrm{Br} J$ Clin Pharmacol. 2013;75:1468-77.

62. Storm C, Schefold JC, Kerner T, et al. Prehospital cooling with hypothermia caps (PreCoCa): A feasibility study. Clin Res Cardiol. 2008;97:768-72.

63. Bjelland TW, Hjertner $\varnothing$, Klepstad P, Kaisen K, Dale O, Haugen BO. Anti-platelet effect of clopidogrel is reduced in patients treated with therapeutic hypothermia after cardiac arrest. Resuscitation. 2010;81:1627-31.

64. Součková L, Opatřilová R, Suk $\mathrm{P}$, et al. Impaired bioavailability and anti-platelet effect of high-dose clopidogrel in patients after cardiopulmonary resuscitation (CPR). Eur J Clin Pharmacol. 2013;69:309-17.

65. Ogu CC, Maxa JL. Drug interactions due to cytochrome P450. Proc (Bayl Univ Med Cent). 2000;13:421-3.

66. Pascoe MC, Howells DW, Crewther DP, et al. Fish oil diet associated with acute reperfusion related hemorrhage, and with reduced stroke-related sickness behaviors and motor impairment. Front Neurol. 2014;5:14.

67. Wachira JK, Larson MK, Harris WS. n-3 Fatty acids affect haemostasis but do not increase the risk of bleeding: clinical observations and mechanistic insights. $\mathrm{Br} J$ Nutr. 2014;111:1652-62.

68. Bradnam V, White R. Handbook of Drug Administration Via Enteral Feeding Tubes, 3rd edition, London, UK: Pharmaceutical Press; 2015.

69. Powers JE, Cascella PJ. Comparison of methods used to prepare tablets for nasogastric tube administration. J Pharm Technol. 1990;6:60-2.

70. Patel V, Kukadiya H, Mashru R, Surti N, Mandal S. Development of microemulsion for solubility enhancement of clopidogrel. Iran J Pharm Res IJPR. 2010;9:327-34.

71. Lenk E, Spannag| M. Platelet function testing - guided antiplatelet therapy. J Int Fed Clin Chem Lab Med. 2013;24:1-7.

72. Breet NJ, Werkum JW van, Bouman HJ, et al. Comparison of Platelet Function Tests Undergoing Coronary Stent Implantation. JAMA. 2010;303:754-62.

73. Paniccia R. Assessment of platelet function: Laboratory and point-of-care methods. World J Transl Med. 2014;3:69.

74. Gladding P, Webster M, Ormiston J, Olsen S, White H. Antiplatelet drug nonresponsiveness. Am Heart J. 2008;155:591-9.

75. Tousoulis D, Siasos G, Stefanadis C. Aspirin resistance: what the cardiologist needs to know? Int J Cardiol. 2009;132:153-6.

76. Michelson AD. Platelets. 2nd ed. 2007;545-63.

77. Gachet C, Aleil B. Testing anti-platelet therapy. Eur Hear J Suppl. 2008;10(Suppl A):A28-34.

78. Harrison P. The role of PFA-100 testing in the investigation and management of haemostatic defects in children and adults. $\mathrm{Br}$ J Haematol. 2005;130:3-10.

79. Hayward CPM, Harrison P, Cattaneo M, Ortel TL, Rao AK. Platelet function analyzer (PFA)-100 closure time in the evaluation of platelet disorders and platelet function. J Thromb Haemost. 2006;4:312-9.

80. Favaloro EJ. Clinical utility of the PFA-100. Semin Thromb Hemost. 2008;34:709-33.

81. Hussein HM, Emiru T, Georgiadis AL, Qureshi Al. Assessment of platelet inhibition by point-of-care testing in neuroendovascular procedures. Am J Neuroradiol. 2013;34:700-6.

82. Aradi D, Storey RF, Komócsi A, et al. Expert position paper on the role of platelet function testing in patients undergoing percutaneous coronary intervention. Eur Heart J. 2014;35:20915.

83. Meybohm P, Zacharowski K, Weber CF. Point-of-care coagulation management in intensive care medicine. Crit Care. 2013;17:218.

84. Adamzik M, Gorlinger K, Peters J, Hartmann M. Whole blood impedance aggregometry as a biomarker for the diagnosis and prognosis of severe sepsis. Crit Care. 2012;16:R204.

85. Short S, Kram B, Taylor S, Cheng J, Ali K, Vasquez D. Effect of platelet inhibition on bleeding complications in trauma patients on preinjury clopidogrel. J Trauma Acute Care Surg. 2013; 74:1419-24.

86. Clareus A, Fredriksson I, Wallén H, Gordon M, Stark A, Sköldenberg $O$. Variability of platelet aggregation in patients with clopidogrel treatment and hip fracture: A retrospective case-control study on 112 patients. World J Orthop. 2015;6:439-45.

87. Rosengart TK, Romeiser JL, White LJ, et al. Platelet activity measured by a rapid turnaround assay identifies coronary artery bypass grafting patients at increased risk for bleeding and transfusion complications after clopidogrel administration. J Thorac Cardiovasc Surg. 2013;146:1259-66, 1266.e1; discussion 1266.

88. Mishra P, Thekkudan J, Sahajanandan R, et al. The role of point-of-care assessment of platelet function in predicting postoperative bleeding and transfusion requirements after coronary artery bypass grafting. Ann Card Anaesth. 2015;18:45.

89. Sibbing D, Braun S, Morath T, et al. Platelet reactivity after clopidogrel treatment assessed with point-of-care analysis and early drug-eluting stent thrombosis. J Am Coll Cardiol. 2009;53:849-56. 